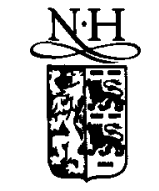

EISEVIER
June 1997

Materials Letters 31 (1997) 271-274

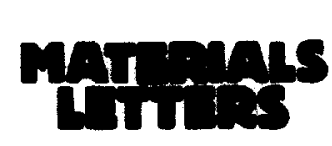

\title{
A new sol-gel route using inorganic salts for synthesizing barium magnesium tantalate ceramics
}

\author{
Chung-Hsin Lu *, Chien-Cheng Tsai \\ Department of Chemical Engineering, National Taiwan University, Taipei, Taiwan, ROC \\ Received 12 November 1996; accepted 15 November 1996
}

\begin{abstract}
A new sol-gel process using inorganic salts instead of metal alkoxides has been successfully developed for preparing $\mathrm{Ba}\left(\mathrm{Mg}_{1 / 3} \mathrm{Ta}_{2 / 3}\right) \mathrm{O}_{3}$. Pure $\mathrm{Ba}\left(\mathrm{Mg}_{1 / 3} \mathrm{Ta}_{2 / 3}\right) \mathrm{O}_{3}$ polycrystalline powders were obtained by calcining the derived precursors at $1100^{\circ} \mathrm{C}$. The particle size of the obtained fine particles was around $0.1 \mu \mathrm{m}$. The ordering parameter of the sintered $\mathrm{Ba}\left(\mathrm{Mg}_{1 / 3} \mathrm{Ta}_{2 / 3}\right) \mathrm{O}_{3}$ was found to strongly depend on the calcination temperatures. Sintering the $1200^{\circ} \mathrm{C}$-calcined powders at $1690^{\circ} \mathrm{C}$ resulted in the ordering parameter to be 0.82 , which is greater than that obtained in the conventional solid-state reaction. The improvement in the ordering parameter is attributed to the enhanced compositional homogeneity in the powders prepared via the sol-gel process.
\end{abstract}

Keywords: $\mathrm{Ba}\left(\mathrm{Mg}_{1 / 3} \mathrm{Ta}_{2 / 3}\right) \mathrm{O}_{3}$; Powder; Sintering; Microstructure; Sol-gel; Inorganic salts; Ordering

\section{Introduction}

Barium magnesiurn tantalate $\left(\mathrm{Ba}\left(\mathrm{Mg}_{1 / 3} \mathrm{Ta}_{2 / 3}\right) \mathrm{O}_{3}\right)$ is well known as an important material utilized at microwave frequencies because it exhibits a high $Q$ value, a low temperature coefficient of resonant constant, and a medium dielectric constant [1]. Despite of these excellent properties of $\mathrm{Ba}\left(\mathrm{Mg}_{1 / 3} \mathrm{Ta}_{2 / 3}\right) \mathrm{O}_{3}$, this material is difficult to sinter even at $1600^{\circ} \mathrm{C}$. Adding appropriate dopants has been found to enhance sintering; however, this addition might deteriorate the microwave properties of $\mathrm{Ba}\left(\mathrm{Mg}_{1 / 3} \mathrm{Ta}_{2 / 3}\right) \mathrm{O}_{3}$ itself [2,3]. An alternative approach from the view point of improving the powder characteristics is using the solution synthesis processes such as the precipitation method [4] and the sol-gel process

\footnotetext{
" Corresponding author
}

using alkoxides [5-9] as raw materials which have demonstrated to produce $\mathrm{Ba}\left(\mathrm{Mg}_{1 / 3} \mathrm{Ta}_{2 / 3}\right) \mathrm{O}_{3}$.

However, in the former process, the synthesis temperature has to be as high as $1300^{\circ} \mathrm{C}$ for the complete formation of $\mathrm{Ba}\left(\mathrm{Mg}_{1 / 3} \mathrm{Ta}_{2 / 3}\right) \mathrm{O}_{3}$. On the other hand, although the sol-gel process using alkoxides can effectively lower the formation temperature, stringent operation conditions and complicated handling procedures are required due to the high sensitivity of alkoxides to moisture. Furthermore, the high cost of alkoxides is unfavorable for mass production.

The purpose of this study is attempting to develop a new sol-gel process using inorganic salts rather than alkoxides as raw materials for preparing $\mathrm{Ba}\left(\mathrm{Mg}_{1 / 3} \mathrm{Ta}_{2 / 3}\right) \mathrm{O}_{3}$ ceramics. The developed process can avoid the complex handling and refluxing of alkoxides. The formation mechanism of $\mathrm{Ba}\left(\mathrm{Mg}_{1 / 3^{-}}\right.$ 
$\left.\mathrm{Ta}_{2 / 3}\right) \mathrm{O}_{3}$ in this process was investigated for adjusting the calcination conditions to produce the pure phase. The effects of calcination temperatures on the sintering density were also examined. In addition, a previously derived equation from the crystallographic view [10] was used to evaluate the ordering parameter of sintered ceramics. Furthermore, the compositional homogeneity in the sol-gel derived powders was compared with that obtained via the conventional solid state reaction process.

\section{Experimental}

The inorganic salts, tantalum chloride and barium and magnesium nitrates, were used as the raw materials to prepare $\mathrm{Ba}\left(\mathrm{Mg}_{1 / 3} \mathrm{Ta}_{2 / 3}\right) \mathrm{O}_{3}$. For removing the chlorine anions in the raw materials, the tantalum chloride was first dissolved in ethanol solution, followed by adding ammonia to precipitate tantalum cations. Then the tantalum hydroxide precipitates were filtered, and repeatedly washed by deionized water. The sol solution of $\mathrm{Ba}\left(\mathrm{Mg}_{1 / 3} \mathrm{Ta}_{2 / 3}\right) \mathrm{O}_{3}$ was prepared by mixing the aqueous solutions of barium and magnesium nitrates with the tantalum hydroxide precipitates at a molar ratio of $\mathrm{Ba}^{2+}: \mathrm{Mg}^{2+}: \mathrm{Ta}^{5+}=$ $3: 1: 2$. Then citric acid and ethylene glycol were added into the mixed sol solution. After drying at $100^{\circ} \mathrm{C}$, the sol solution transformed into an xerogel. On further drying at $300^{\circ} \mathrm{C}$, the precursors having a fine powder form were obtained. These precursors were heated in air from $300^{\circ} \mathrm{C}$ to $1200^{\circ} \mathrm{C}$ with or without soaking. The phasic identification and structural analysis for the heated samples were performed via X-ray powder diffraction (XRD) using $\mathrm{Cu} \mathrm{K \alpha}$ radiation. The powders calcined at different temperatures were uniaxially pressed into pellets and sintered at $1690^{\circ} \mathrm{C}$ for $2 \mathrm{~h}$. After sintering, the density and the ordering parameter $(S)$ of the sintered compacts were measured. The microstructures of the sintered compacts were observed by scanning electron microscopy (SEM). The chemical composition of the specimens was analyzed via energy dispersive spectroscopy (EDS).

\section{Results and discussion}

The precursors were heated and quenched at temperatures ranging from $300^{\circ} \mathrm{C}$ to $950^{\circ} \mathrm{C}$. At $300^{\circ} \mathrm{C}$ only $\mathrm{BaCO}_{3}$ existed in the samples. After heating up to $500^{\circ} \mathrm{C}$, the major diffraction peak $(110)$ of $\mathrm{Ba}\left(\mathrm{Mg}_{1 / 3} \mathrm{Ta}_{2 / 3}\right) \mathrm{O}_{3}$ was observed, indicating the beginning of $\mathrm{Ba}\left(\mathrm{Mg}_{1 / 3} \mathrm{Ta}_{2 / 3}\right) \mathrm{O}_{3}$ formation. This temperature for the initiation of the formation of $\mathrm{Ba}\left(\mathrm{Mg}_{1 / 3} \mathrm{Ta}_{2 / 3}\right) \mathrm{O}_{3}$ in the sol-gel process was found to be $190^{\circ} \mathrm{C}$ lower than that in the solid-state reaction [10]. With an increase in the heating temperatures, the formation amount of $\mathrm{Ba}\left(\mathrm{Mg}_{1 / 3} \mathrm{Ta}_{2 / 3}\right) \mathrm{O}_{3}$ increased, accompanied with a reduction in the amount of $\mathrm{BaCO}_{3}$. When heating up to $950^{\circ} \mathrm{C}$, the majority of $\mathrm{Ba}\left(\mathrm{Mg}_{1 / 3} \mathrm{Ta}_{2 / 3}\right) \mathrm{O}_{3}$ was produced; however, a small amount of $\mathrm{BaCO}_{3}$ still remained. In the formation processes, only $\mathrm{BaCO}_{3}$ was found to exist as an intermediate.

For obtaining the pure phase of $\mathrm{Ba}\left(\mathrm{Mg}_{1 / 3^{-}}\right.$ $\left.\mathrm{Ta}_{2 / 3}\right) \mathrm{O}_{3}$, isothermal calcination at different temperatures for $2 \mathrm{~h}$ was conducted. Fig. 1 shows the diffraction patterns of calcined powders. After calcination at $900^{\circ} \mathrm{C}$, the coexistence of $\mathrm{BaCO}_{3}$ and a small amount of $\mathrm{Ba}\left(\mathrm{Mg}_{1 / 3} \mathrm{Ta}_{2 / 3}\right) \mathrm{O}_{3}$ was observed. At $1000^{\circ} \mathrm{C}$, the amount of $\mathrm{BaCO}_{3}$ decreased. After $1100^{\circ} \mathrm{C}$ calcination, only pure $\mathrm{Ba}\left(\mathrm{Mg}_{1 / 3} \mathrm{Ta}_{2 / 3}\right) \mathrm{O}_{3}$ was identified. This result indicates that using the developed sol-gel process can successfully synthesize $\mathrm{Ba}\left(\mathrm{Mg}_{1 / 3} \mathrm{Ta}_{2 / 3}\right) \mathrm{O}_{3}$. It is also noted that the

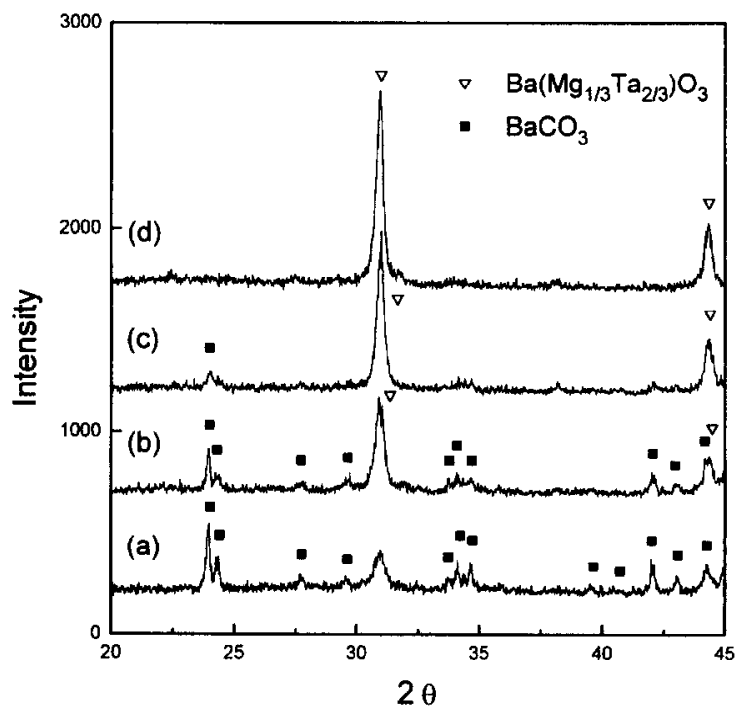

Fig. 1. X-ray diffraction patterns of the $\mathrm{Ba}\left(\mathrm{Mg}_{1 / 3} \mathrm{Ta}_{2 / 3}\right) \mathrm{O}_{3}$ precursors obtained from the sol-gel process calcined at (a) $700^{\circ} \mathrm{C}$, (b) $900^{\circ} \mathrm{C}$, (c) $1000^{\circ} \mathrm{C}$ and (d) $1100^{\circ} \mathrm{C}$. 
temperature for the complete formation of $\mathrm{Ba}\left(\mathrm{Mg}_{1 / 3} \mathrm{Ta}_{2 / 3}\right) \mathrm{O}_{3}$ in this process is lower than that in the precipitation process [4]. The morphology of the obtained pure $\mathrm{Ba}\left(\mathrm{Mg}_{1 / 3} \mathrm{Ta}_{2 / 3}\right) \mathrm{O}_{3}$ powders was observed via SEM. As shown in Fig. 2a, these powders exhibited a fine microstructure with a small particle size around $0.1 \mu \mathrm{m}$. In comparison with the powders obtained from the solid-state reaction (see Fig. 2b) [10], the $\mathrm{Ba}\left(\mathrm{Mg}_{1 / 3} \mathrm{Ta}_{2 / 3}\right) \mathrm{O}_{3}$ powders synthesized via the sol-gel process apparently had a smaller particle size and a narrower size distribution.

The powders calcined at different temperatures were pressed into pellets, followed by sintering at $1690^{\circ} \mathrm{C}$ for $2 \mathrm{~h}$. The relation between the sintering density and the calcination temperature is depicted in

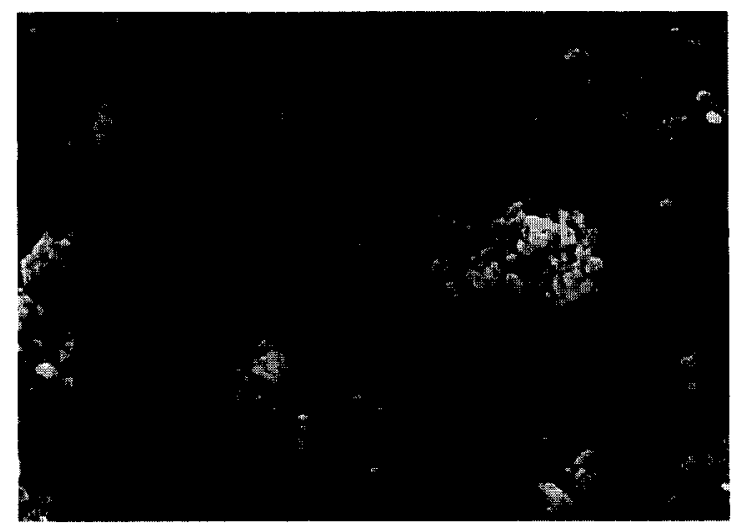

(a)

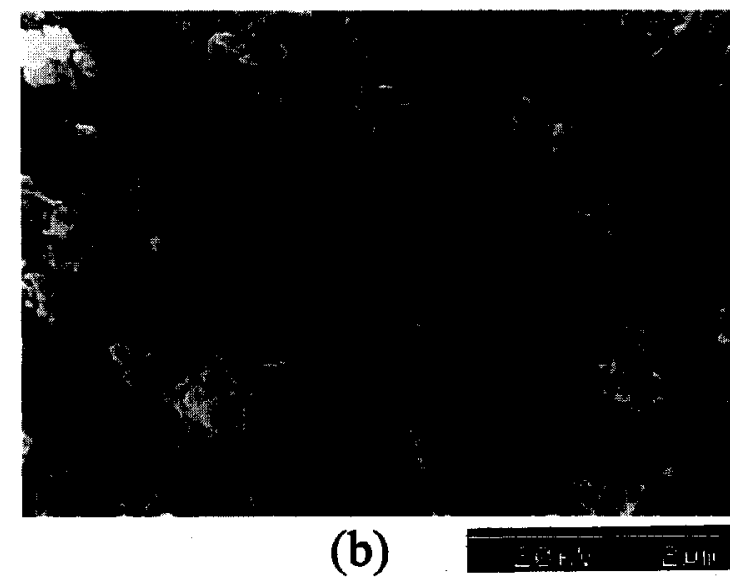

Fig. 2. Scanning electron micrographs of $\mathrm{Ba}\left(\mathrm{Mg}_{1 / 3} \mathrm{Ta}_{2 / 3}\right) \mathrm{O}_{3}$ obtained from (a) the sol-gel process and (b) the solid state reaction.

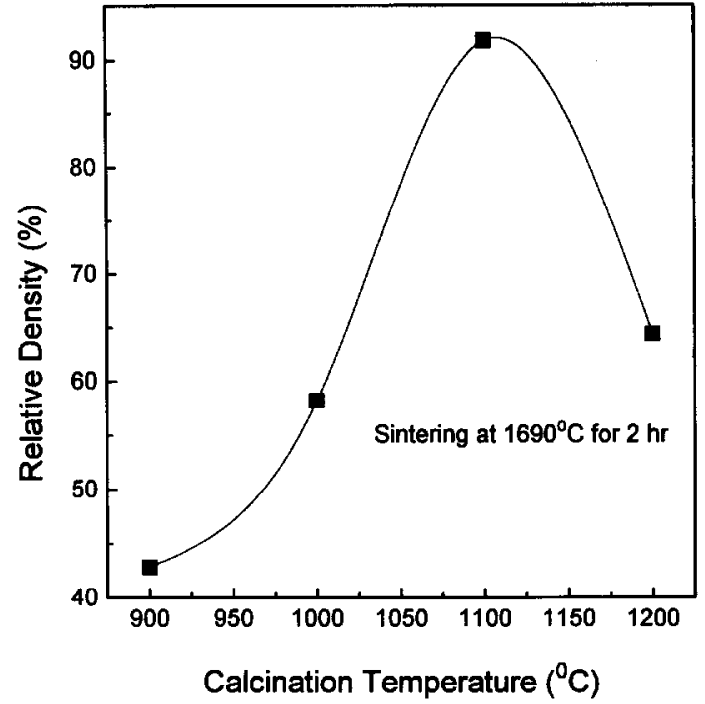

Fig. 3. Calcination temperature versus the sintering density of $\mathrm{Ba}\left(\mathrm{Mg}_{1 / 3} \mathrm{Ta}_{2 / 3}\right) \mathrm{O}_{3}$.

Fig. 3. The sintering densities of the precursors calcined at $900^{\circ} \mathrm{C}$ and $1000^{\circ} \mathrm{C}$ were only $43 \%$ and $58 \%$, respectively. On the other hand, the calcination at $1100^{\circ} \mathrm{C}$ provided the sintered body with a maximum density (92\%). However, once the powders were calcined at $1200^{\circ} \mathrm{C}$, the sintering density dropped to $65 \%$. According to the results in Fig. 1, after calcination at $900^{\circ} \mathrm{C}$ and $1000^{\circ} \mathrm{C}, \mathrm{BaCO}_{3}$ still remained in the samples. During the sintering process, the evolution of carbon dioxide from $\mathrm{BaCO}_{3}$ tended to cause the expansion and de-sintering behavior of the compacts, thereby impeding the sintering process. Once $\mathrm{BaCO}_{3}$ is completely consumed to form $\mathrm{Ba}\left(\mathrm{Mg}_{1 / 3} \mathrm{Ta}_{2 / 3}\right) \mathrm{O}_{3}$, the negative effect of $\mathrm{BaCO}_{3}$ on sintering can be avoided. However, overcalcination at $1200^{\circ} \mathrm{C}$ resulted in unfavorable grain growth which reduced the sinterability of the powders. Similar effects of calcination temperatures on sintering were also observed in alkoxide-derived $\mathrm{Ba}\left(\mathrm{Mg}_{1 / 3} \mathrm{Ta}_{2 / 3}\right) \mathrm{O}_{3}$ [9].

In the $1690^{\circ} \mathrm{C}$-sintered samples, the diffraction peaks originating from the superlattice structure were observed. The appearance of these diffraction peaks implies that the crystalline structure of $\mathrm{Ba}\left(\mathrm{Mg}_{1 / 3} \mathrm{Ta}_{2 / 3}\right) \mathrm{O}_{3}$ transformed from a random state into a partially orderly state. For calculating the ordering parameter $(S)$ of these sintered samples, an 
equation derived from the crystallographic view was used [10]. This equation is expressed as

$S=[46.91 Y /(3.82-Y)]^{1 / 2}$,

where $Y$ is equal to the value of $I_{100}\left(I_{110}+I_{102}+\right.$ $I_{012}$ ). Fig. 4 illustrates the relation of the ordering parameter versus the calcination temperature. This figure indicates that increasing the calcination temperature effectively raised the ordering parameter. When the precursors were calcined at $1200^{\circ} \mathrm{C}$, the ordering parameter of the sintered samples reached 0.82. Applying the same sintering process on the powders prepared via the solid state reaction only obtained $S=0.61$ [10]. The ordering parameter in the sol-gel process is much greater than that in the conventional process. For realizing the reason for the increase in the ordering parameter, EDS was used to analyze the chemical composition of the sintered samples obtained from both processes. In the solid state reaction, the ratios of the standard deviation of the molar percent to the average value of the molar percent for $\mathrm{Ba}, \mathrm{Mg}$, and $\mathrm{Ta}$ species in grains were $0.109,0.143$ and 0.219 , respectively. Whereas in the sol-gel process, these ratios in turn were reduced to be $0.066,0.079$ and 0.151 , respectively. This result

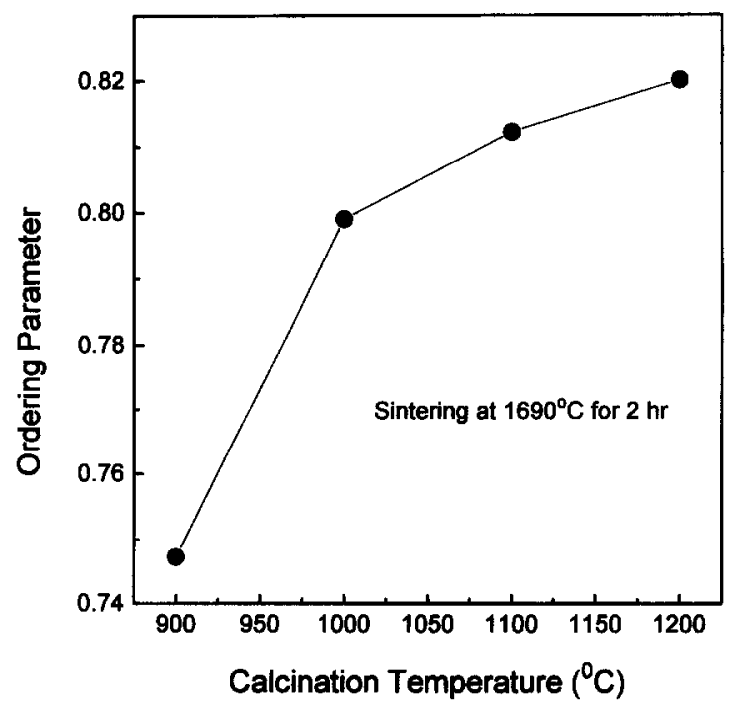

Fig. 4. Calcination temperature versus the ordering parameter of $\mathrm{Ba}\left(\mathrm{Mg}_{1 / 3} \mathrm{Ta}_{2 / 3}\right) \mathrm{O}_{3}$. reveals that the fluctuation of composition was markedly reduced in the sol-gel derived powders. In other words, the compositional homogeneity was improved in the sol-gel process. The improved compositional homogeneity is considered to contribute to the rise in the ordering parameter.

\section{Conclusion}

Pure $\mathrm{Ba}\left(\mathrm{Mg}_{1 / 3} \mathrm{Ta}_{2 / 3}\right) \mathrm{O}_{3}$ powders were successfully synthesized via the developed sol-gel process using inorganic salts as raw materials. The formation of $\mathrm{Ba}\left(\mathrm{Mg}_{1 / 3} \mathrm{Ta}_{2 / 3}\right) \mathrm{O}_{3}$ started from $500^{\circ} \mathrm{C}$, and was complete after $1100^{\circ} \mathrm{C}$-calcination. The particle size of the obtained powders was around $0.1 \mu \mathrm{m}$. During the calcination process, $\mathrm{BaCO}_{3}$ existed as the only intermediate compound. Increasing the calcination temperature significantly enhanced the ordering parameter of the sintered $\mathrm{Ba}\left(\mathrm{Mg}_{1 / 3} \mathrm{Ta}_{2 / 3}\right) \mathrm{O}_{3}$. When the $1200^{\circ} \mathrm{C}$-calcined powders were sintered at $1690^{\circ} \mathrm{C}$, the ordering parameter reached a maximum of 0.82 . This value is much greater than that obtained by the conventional solid-state reaction. The enhanced compositional homogeneity in the sol-gel process is considered to result in the increase in the ordering parameter.

\section{References}

[1] S. Nomura, K. Toyama and K. Kaneta, Japan. J. Appl. Phys. 21 (1982) L624.

[2] E.S. Kim and K.H. Yoon, J. Mater. Sci. 29 (1994) 830.

[3] K.H. Yoon, D.P. Kim and E.S. Kim, J. Am. Ceram. Soc. 77 (1994) 1062.

[4] K. Kakegawa, T. Wakabayashi and Y. Sasaki, J. Am. Ceram. Soc. 69 (1986) C82.

[5] T. Fukui, C. Sakurai and M. Okuyama, J. Mater. Res. 7 (1992) 1883.

[6] S. Katsyama and M. Sekine, J. Mater. Chem. 2 (1992) 889.

[7] O. Renoult, J.P. Boilot, F. Chaput, R. Papiernik, L.G. Hubert-Pfalzgraf and M. Lejeune, J Am. Ceram. Soc. 75 (1992) 3337.

[8] D. Ravichandran, B. Jin, R. Roy and A.S. Bhalla, Mater. Lett. 25 (1995) 257.

[9] S. Katayama, I. Yoshinaga, N. Yamada and T. Nagai, J. Am. Ceram. Soc. 79 (1996) 2059. 